\title{
Anthropometric Study on Chinese Head
}

\author{
Roger MacLaren BALL, Yan LUXIMON*, Ho Chi Eric CHOW \\ School of Design, The Hong Kong Polytechnic University, Hong Kong
}

\begin{abstract}
Head and facial anthropometry of the Caucasian general population has long been surveyed and analyzed in numerous studies in the Western world. Similar studies have been performed in mainland China, but only specifically on the military, pilots and workers. This paper presents the results of a recent anthropometric survey conducted by SizeChina on a more general population in mainland China. A total of 1563 samples were selected, which covers a full range of ages from 18 to 71+, in both genders, from six cities in China. The current study analyzes the body height, body weight, head circumference, head length and head breadth. Normality tests were performed and most of dimensions follow normal distributions. The simple statistics by gender group, age group and location group are shown. It was found that all three head dimensions, the circumference, the length and the breadth of male are larger than those of female. Age group does demonstrate differences in terms of the head length and head breadth. In addition, there are significant differences in head dimensions among different geographic locations.
\end{abstract}

Keywords: anthropometry, Chinese, 3D head scanning

\section{Introduction}

Anthropometric studies on Western populations, such as those conducted and documented by Annis [1], Bradtmiller et al. [2], and Gordon [3], have been readily available for many years. However, anthropometric information for Chinese populations remains scarce. Du et al. [4], Liu et al. [5] and Xia et al. [6] have attempted to fill this gap, but their data were collected from very specific population; the studies by Liu et al. and Xia et al. focused primarily on the military and Chinese male pilots, while the study by Du et al. sampled only Chinese workers with its sample size biased towards the male population. SizeChina is a project that aims to fill the gap by conducting and analyzing anthropometric survey on the general Chinese civilian population, with an equal mix on male and female. In 2006, SizeChina surveyed and collected traditional anthropometric measurements and 3D digital scans of Chinese head and face shape from more than 2000 subjects across six locations in mainland China. Using the SizeChina 3D anthropometric dataset and that of the CAESAR project [7] on the western population, the authors have recently published a comparative study [8] that shows Chinese heads can be generally characterized as rounder than their Western counterparts, with a flatter back and forehead. This paper, on the other hand, makes use of the traditional anthropometric data collected from the SizeChina survey to reveal the characteristics of Chinese head dimensions across genders, age groups, and geographic regions in China.

\section{Methods}

\subsection{Participants}

Recruiting of the subjects was done from six locations in China by the local liaison officer. Subjects were volunteers and recruited randomly. More than 2000 adults participated and a total of 1563 scans (783 male, 780 female) were selected after deleting missing data. At each site, sample size succeeded covering a full range of ages from 18 to $71+$, in both genders. The subjects included 11 different ethnic groups but the final data contained 95.1\% Han ethnic group. Figure 1 shows the age range and gender distribution among the six different locations.

\footnotetext{
*sdtina@polyu.edu.hk
} 


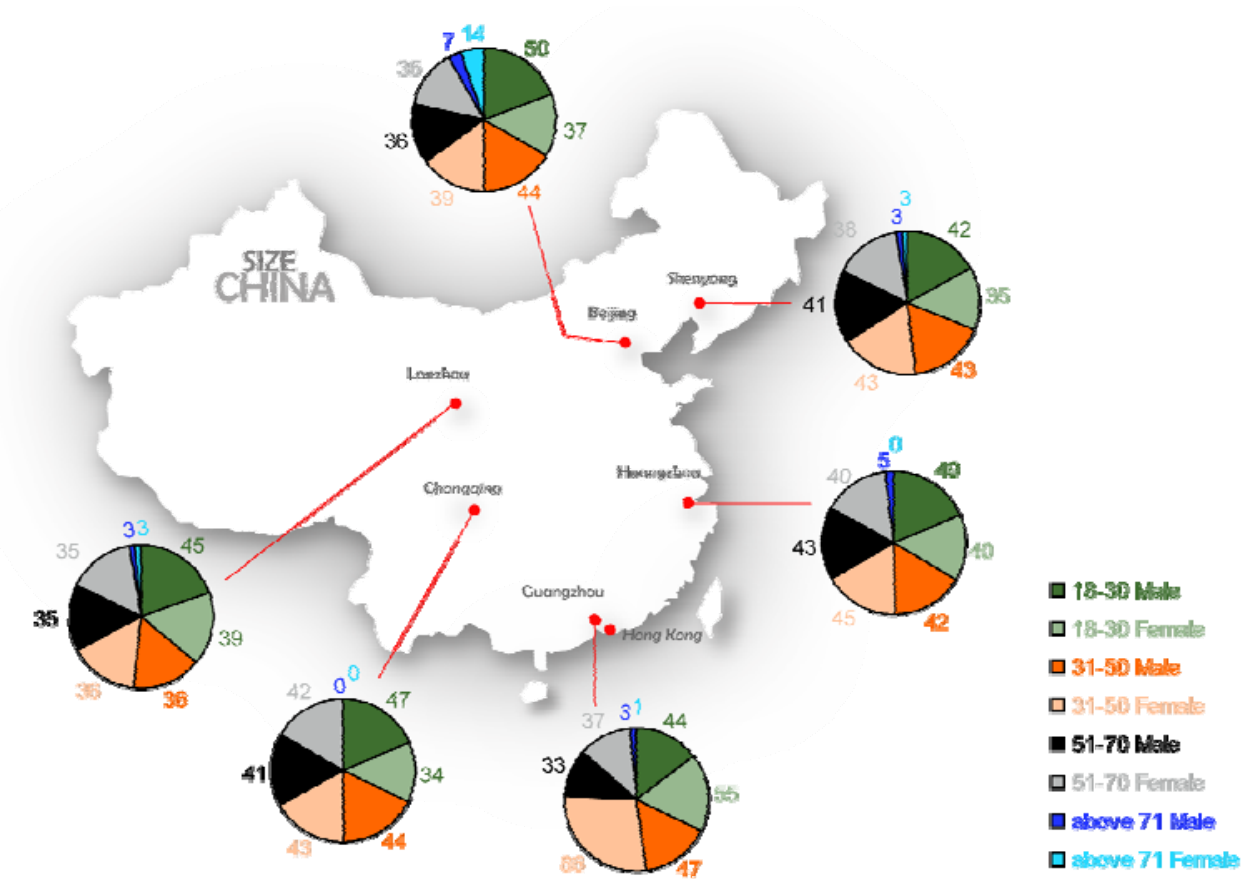

Fig. 1. Age range and gender distribution of the six locations from which subjects were recruited.

\subsection{Apparatus}

Anthropometer and tape were used to record physical head dimensions of the subjects. Medical quality scales, which were calibrated at each site to ensure accuracy and consistency, were used to measure height and weight of the subjects. The Cyberware 3030 Head \& Face Color 3D Laser Scanner (http://www.cyberware.com) was used to collect 3D shape measurements of the head and face. The scanner was transported to each of the six locations to perform 3D shape measurement. The scanner has a sampling rate of around 30,000 points per second. In addition, a tight fitting nylon wig cap was put onto each subject's head when performing the head scan. The wig cap compresses the excess volume of fluffy hair styles, which better revealed the underlying shape of the head.

\subsection{Procedure}

Each subject was first given an introduction of the scanning process in Chinese, and was asked to fill out basic information regarding their age, gender, family background, the location where they grew up, and so forth. Then, the anthropometric measurements were recorded for each subject. Height and weight were measured with a medical quality scale, which was calibrated at each site to ensure accuracy and consistency. Measurements of the length and width of the head were taken using an anthropometer, and the circumference of the head was measured using a tape. Fourteen facial landmarks were placed onto each subject's face using 5-mm adhesive-backed red dot. These landmarks are used to compute facial measurement from the 3D scans in later analysis. The following facial landmarks were marked: Chin, Frontotemporale (right and left), Glabella, Infraorbitale (right and left), Pronasale, Sellion, Tragion (right and left), Zygion (right and left), Zygofrontale (right and left). After putting on the wig cap, the subject is seated on the chair placed on a rotating platform. The subject is asked to sit still in an upright and relaxed posture, breath normally, eyes kept open. When the subject is ready in such posture, the scanner is started, and takes 17 seconds to complete a full revolution around the head.

\section{Results}

\subsection{Simple Statistics}

Shapiro-Wilk normality tests are performed on the body height, body weight, head circumference, head length and head breadth. All dimensions from all age group and gender follow normal distributions, except body height for age group 31-50 ( $p>0.15)$, head circumference for age group 51$70(p>0.05)$ and head length for age group 51-70 ( $p>0.05)$. The simple statistics of each body dimension are shown in Table 1. Statistics grouped by gender, age and location are shown in Tables $2-4$. 
Table 1: Simple statistics of head and body measurements from SizeChina survey

\begin{tabular}{|c|c|c|c|c|c|}
\hline Variable & $\mathbf{N}$ & Mean & Std Dev & Minimum & Maximum \\
\hline Body Height (mm) & \multirow{5}{*}{1563} & 1612 & 84 & 1371 & 1933 \\
\hline Body Weight $(\mathrm{kg})$ & & 60 & 11 & 32 & 126 \\
\hline Head Circumference (mm) & & 555 & 18 & 503 & 635 \\
\hline Head Length (mm) & & 184 & 8 & 149 & 215 \\
\hline Head Breadth (mm) & & 155 & 8 & 130 & 179 \\
\hline
\end{tabular}

Table 2: Simple statistics by gender group for adult

\begin{tabular}{|c|c|c|c|c|c|c|}
\hline & Variable & $\mathbf{N}$ & Mean & Std Dev & Minimum & Maximum \\
\hline \multirow{5}{*}{ Male } & Body Height (mm) & \multirow{5}{*}{783} & 1667 & 69 & 1412 & 1933 \\
\hline & Body Weight (kg) & & 65 & 11 & 38 & 126 \\
\hline & Head Circumference (mm) & & 565 & 16 & 513 & 635 \\
\hline & Head Length (mm) & & 188 & 7 & 163 & 215 \\
\hline & Head Breadth (mm) & & 158 & 7 & 133 & 179 \\
\hline \multirow{5}{*}{ Female } & Body Height (mm) & \multirow{5}{*}{780} & 1556 & 58 & 1371 & 1750 \\
\hline & Body Weight (kg) & & 56 & 9 & 32 & 98 \\
\hline & Head Circumference (mm) & & 546 & 14 & 503 & 597 \\
\hline & Head Length (mm) & & 180 & 7 & 149 & 203 \\
\hline & Head Breadth (mm) & & 151 & 6 & 130 & 171 \\
\hline
\end{tabular}

Table 3: Simple statistics by age group for adult

\begin{tabular}{|c|c|c|c|c|c|c|}
\hline & Variable & $\mathbf{N}$ & Mean & Std Dev & Minimum & Maximum \\
\hline \multirow{5}{*}{$18-30$} & Body Height $(\mathrm{mm})$ & \multirow{5}{*}{517} & 1640 & 85 & 1440 & 1933 \\
\hline & Body Weight (kg) & & 58 & 11 & 36 & 126 \\
\hline & Head Circumference (mm) & & 557 & 18 & 503 & 617 \\
\hline & Head Length (mm) & & 183 & 8 & 162 & 211 \\
\hline & Head Breadth (mm) & & 157 & 8 & 137 & 179 \\
\hline \multirow{5}{*}{$31-50$} & Body Height $(\mathrm{mm})$ & \multirow{5}{*}{548} & 1603 & 78 & 1403 & 1853 \\
\hline & Body Weight (kg) & & 61 & 10 & 34 & 93 \\
\hline & Head Circumference $(\mathrm{mm})$ & & 555 & 18 & 505 & 610 \\
\hline & Head Length (mm) & & 184 & 8 & 164 & 207 \\
\hline & Head Breadth (mm) & & 154 & 7 & 133 & 178 \\
\hline \multirow{5}{*}{$51-70$} & Body Height $(\mathrm{mm})$ & \multirow{5}{*}{456} & 1592 & 82 & 1371 & 1851 \\
\hline & Body Weight (kg) & & 62 & 11 & 32 & 98 \\
\hline & Head Circumference (mm) & & 555 & 17 & 515 & 635 \\
\hline & Head Length (mm) & & 186 & 8 & 149 & 215 \\
\hline & Head Breadth (mm) & & 153 & 7 & 130 & 178 \\
\hline \multirow{5}{*}{$71+$} & Body Height (mm) & \multirow{5}{*}{42} & 1580 & 82 & 1398 & 1750 \\
\hline & Body Weight (kg) & & 63 & 13 & 35 & 96 \\
\hline & Head Circumference (mm) & & 553 & 22 & 509 & 608 \\
\hline & Head Length (mm) & & 186 & 9 & 170 & 208 \\
\hline & Head Breadth (mm) & & 154 & 9 & 138 & 171 \\
\hline
\end{tabular}


Table 4: Simple statistics by location group for adult

\begin{tabular}{|c|c|c|c|c|c|c|}
\hline & Variable & $\mathbf{N}$ & Mean & Std Dev & Minimum & Maximum \\
\hline \multirow{5}{*}{ Beijing } & Body Height (mm) & \multirow{5}{*}{262} & 1637 & 86 & 1435 & 1876 \\
\hline & Body Weight (kg) & & 64 & 12 & 35 & 126 \\
\hline & Head Circumference $(\mathrm{mm})$ & & 558 & 18 & 509 & 617 \\
\hline & Head Length (mm) & & 184 & 8 & 164 & 208 \\
\hline & Head Breadth (mm) & & 157 & 7 & 136 & 177 \\
\hline \multirow{5}{*}{ Chongqing } & Body Height (mm) & \multirow{5}{*}{251} & 1575 & 83 & 1378 & 1785 \\
\hline & Body Weight (kg) & & 57 & 10 & 32 & 88 \\
\hline & Head Circumference $(\mathrm{mm})$ & & 553 & 18 & 505 & 635 \\
\hline & Head Length $(\mathrm{mm})$ & & 185 & 8 & 163 & 215 \\
\hline & Head Breadth (mm) & & 153 & 7 & 135 & 178 \\
\hline \multirow{5}{*}{ Guangzhou } & Body Height (mm) & \multirow{5}{*}{306} & 1607 & 80 & 1371 & 1933 \\
\hline & Body Weight (kg) & & 58 & 10 & 36 & 93 \\
\hline & Head Circumference $(\mathrm{mm})$ & & 554 & 17 & 514 & 608 \\
\hline & Head Length (mm) & & 184 & 7 & 164 & 208 \\
\hline & Head Breadth (mm) & & 153 & 7 & 133 & 175 \\
\hline \multirow{5}{*}{ Hangzhou } & Body Height $(\mathrm{mm})$ & \multirow{5}{*}{264} & 1620 & 79 & 1420 & 1890 \\
\hline & Body Weight (kg) & & 60 & 10 & 40 & 99 \\
\hline & Head Circumference $(\mathrm{mm})$ & & 557 & 19 & 503 & 608 \\
\hline & Head Length (mm) & & 186 & 8 & 149 & 211 \\
\hline & Head Breadth (mm) & & 156 & 8 & 130 & 179 \\
\hline \multirow{5}{*}{ Lanzhou } & Body Height (mm) & \multirow{5}{*}{232} & 1606 & 82 & 1391 & 1816 \\
\hline & Body Weight (kg) & & 58 & 10 & 40 & 86 \\
\hline & Head Circumference $(\mathrm{mm})$ & & 557 & 16 & 511 & 608 \\
\hline & Head Length (mm) & & 184 & 8 & 162 & 210 \\
\hline & Head Breadth (mm) & & 151 & 8 & 136 & 176 \\
\hline \multirow{5}{*}{ Shenyang } & Body Height (mm) & \multirow{5}{*}{248} & 1625 & 84 & 1398 & 1828 \\
\hline & Body Weight (kg) & & 63 & 12 & 38 & 98 \\
\hline & Head Circumference $(\mathrm{mm})$ & & 554 & 19 & 505 & 608 \\
\hline & Head Length (mm) & & 181 & 9 & 164 & 202 \\
\hline & Head Breadth (mm) & & 158 & 7 & 142 & 175 \\
\hline
\end{tabular}

A recent study by Du et al. [4] surveyed head and face dimensions of Chinese workers, and revealed the head circumferences (mean for male $=567.0 \mathrm{~mm}$; mean for female $=546.2 \mathrm{~mm}$ ), head length $($ mean for male $=185.7 \mathrm{~mm}$; mean for female $=176.7 \mathrm{~mm}$ ) and head breadth (mean for male $=157.2$ $\mathrm{mm}$; mean for female $=150.5 \mathrm{~mm}$ ) of these Chinese workers. Clearly, the results from Du's survey are very similar to the data obtained by the current study.

\subsection{ANOVA results}

One way ANOVA reveals that Chinese male have significant larger head measurement than female in terms of head circumference $\left(F_{1,1561}=608.67 ; p<0.0001\right)$, head length $\left(F_{1,1561}=597.12 ; p<0.0001\right)$ and head breadth $\left(F_{1,1561}=475.78 ; p<0.0001\right)$.

There is no significant difference across the four age groups $\left(F_{3,1559}=1.33, p=0.2637\right)$ in terms of head circumference. However, in terms of head length, there is significant difference among the four age groups $\left(F_{3,1559}=13.39 ; p<0.0001\right)$. The head length of older adults aged 51 to $71+$ are longer than that of adults aged 18 to 50 . For the head breadth, there is also a significant difference across age groups $\left(F_{3,1559}=21.54, p<0.0001\right)$. It is found that adults aged 18-30 have larger head breadth than all other age groups (31 to $71+$ ).

Results from one way ANOVA also show that people from different geographic regions have significantly different head circumference $\left(F_{5,1557}=3.39, p=0.0047\right)$, head length $\left(F_{5,1557}=11.82\right.$, $p<0.0001)$ and head breadth $\left(F_{5,1557}=41.15, p<0.0001\right)$. Samples from Northern (Beijing), Western (Lanzhou) and Eastern China (Hangzhou) have larger head circumference than those of Southern 
(Guangzhou), West-Southern (Chongqing) and Far-Northern China (Shenyang). On the other hand, people from Eastern China have longer head length than people from other regions. Finally, samples from Northern and Far-Northern China have larger head breadth than those from Southern, WestSouthern and Western China.

\section{Conclusion}

SizeChina collected 2000 traditional anthropometric measurements and high resolution 3D head and face scans from subjects in six locations across mainland China. Statistical analysis reveals significance difference in certain head dimensions across genders, particular age groups and geographic regions. It is found that male has a larger head size than female. Young adults (18-30 years old) tend to have a larger head breadth, while older adults (51-71+ years old) tend to have longer head length.

There is a general perception that the Northern-Chinese population generally has a larger body size than that of other parts of the country. However, this study does not completely support this perception in terms of head size. Although people from Northern China have larger head breadth, the current study also reveals that people from Northern, Western and Eastern China have larger head circumference, while those from Eastern China have longer head length.

Comparison between the data from current study and those from a recent survey by Bradtmiller et al. [2] shows that the Chinese population has a smaller mean head circumference than the United States population (Chinese $=555 \mathrm{~mm}$; US $=568 \mathrm{~mm}$ ). This is also true for mean head length (Chinese $=$ $184 \mathrm{~mm}$; US $=193 \mathrm{~mm}$ ). On the other hand, Chinese people tend to have slightly larger mean head breadth (Chinese $=154 \mathrm{~mm}$; US $=150 \mathrm{~mm}$ ).

The findings of this study serve as a valuable reference for product designers who can now place less reliance on Western head size data, and produce headwear designs that are more physically fit for the Chinese population. Future studies that compare individual facial dimensions between Western and Chinese population will also be extremely useful for the headwear design community. Using a combination of head anthropometry and genetics data, future research may also possibly trace the origin of different ethnic groups. In the area of anthropology, head anthropometric data obtained from current study may offer insights into how differences in head shape may relate to social customs or environmental factors in China.

\section{Acknowledgments}

The authors would like to thank the SizeChina and the Hong Kong Polytechnic University for supporting this work through Postdoctoral fellowship scheme and Schoolboard Chairman Reserve.

\section{References}

1. Annis, J. F., (1978): "Anthropometric Sourcebook, Volume 1: Anthropometry for Designers", Houston, USA: NASA - Reference Publication 1024.

2. Bradtmiller, B., Zhuang, Z., (2005): "Head-and-Face Anthropometric Survey of US Respirator Users", Journal of Occupational and Environmental Hygiene, Vol. 2, No.11, pp.567-576.

3. Gordon, C., (1996): "US Army Anthropometric Survey Database: Downsizing, Demographic Change and Validity of the 1988 Data in 1996", MA, USA: Natick Research, Development and Engineering Center.

4. Du, L., Zhuang, Z., Guan, H., Xing, J., Tang, X., Wang, L., Wang, Z., Wang, H., Liu, Y., Su, W., Benson, S., Gallagher, S., Viscusi, D., Chen, W., (2008): "Head-and-Face anthropometric survey of Chinese workers", The Annals of Occupational Hygiene, Vol.52, No.8, pp.773-782.

5. Liu, B. S., Guo, X., Ma, X., (2002): "Character of Anthropometry Usefulness for Chinese Male Pilot", Chinese Ergonomics, Vol.8, No.4, pp.1-3.

6. Xia, P., Zeng, C., Jiang, Z., Huang, Y., (2001): “Determination of Sample Size for Serviceman's Body Measurements Database", Journal of Textile Research, Vol.22, No.2, pp 80.

7. Robinette, K. M., Daanen, H., (1999): "The CAESAR Project: A 3D Surface Anthropometry Survey", Second International Conference on 3-D Imaging and Modeling (3DIM '99), Ottawa, Canada. pp. 380.

8. Ball, R., Shu, C., Xi, P., Rioux, M., Luximon, Y., Molenbroek, J., (2010): "A comparison between Chinese and Caucasian head shapes", Applied Ergonomics, Vol.41, No.6, pp. 832-839. 